\section{Touching the right chord}

Disease in a Minor Chord. By E. A. Steinhaus. Pp. xviii +488 . (Ohio State University: Columbus, August 1975.) $\$ 20$.

THE late Edward Steinhaus has come to be regarded as perhaps the most significant 'founding father' of invertebrate pathology. This book was intended, in his own words, to be "semihistorical and semi-biographical", but was never finished because Steinhaus died in 1969. His widow, Mrs Mabry Steinhaus and one of his colleagues at Berkeley, Dr Mauro Martignoni, however, wisely did not attempt to complete the manuscript but instead concentrated on preparation for publication. The result is a book, presented with care and sympathy, which makes for fascinating reading.

Readers not familiar with this field may be surprised to learn of the struggle that Steinhaus had to obtain recognition for the importance and scientific merit of studies on diseases of insects and other invertebrates. Insects alone account for about $75 \%$ of the known animal species in the world and are man's greatest competitor for food as well as transmitting some of his most troublesome diseases. Nevertheless, the study of insect diseases remained an esoteric subject known to few men and scarcely at all to science until the late $1940 \mathrm{~s}$. It was typical of the period that when Steinhaus required a class text on insect pathology, none was available, so he had to write one himself

Chapter 1 deals with the early history of insect pathology reaching into Greek science and ending in Chapter 2 with developments in immediate post World War II period. These two chapters will become prescribed reading for any student wishing to study the history of insect pathology. In Chapter 3 the significant contribution made by Californian workers is recounted. The prose in this chapter is perhaps the best in the book and it is the one in which we begin to know Steinhaus as the man rather than a familiar name in the literature. We can share his frustrations and also identify with his ambitions. Anyone who has tried to develop novel and possibly unconventional ideas cannot fail to have understanding, sympathy, but above all admiration for the task that Steinhaus set himself in California. We can rejoice that these hopes and aspirations were largely achieved, although not without pain and anguish. It is true that many major developments in insect pathology have appeared since 1969 but nevertheless it must be acknowledged that the scene for these advancements was set largely by Steinhaus.

Chapter 4 presents an interesting, although inevitably incomplete, account of the European contribution to the knowledge of insect diseases, and in Chapter 5 we have Steinhaus' real and sometimes painful introduction to the intricacies of European scientific politics. Steinhaus the Editor was the creative force behind a scientific journal (J. Insect Path., now J. invert. Path.) and an annual review ( $A$. Rev. Ent.) which have for many years now been accredited with international standing and the background story to these developments is given in Chapter 6.

It says much for the style and presentation of this book that it can be read and enjoyed by professional and layman alike and as such can be recommended to all.

T. W. Tinsley

\section{Fungal development}

An Introduction to the Biochemistry of Fungal Development. By J. E. Smith and D. R. Berry, pp. 326 (Academic: London and New York, 1975.) £9.50; $\$ 20.75$.

Although few would deny that there are areas of molecular biology that require consolidation with further research, many molecular biologists (or are they microbial physiologists?) have turned to the comparatively virgin domain of microbial differentiation for a fresh challenge. Differentiation in micro-organisms is rather difficult to define, but fundamentally it entails the formation of morphologically different structures from vegetative organisms. Most microbiologists would go along with the great pioneer of research into biological differentiation, John Tylcr Bonner, who believes that differentiation in organisms must be studied for the knowledge that it provides about those organisms. Nevertheless, many biologists who have turned to problems in microbial differentiation have done sc because the system they have chosen to study provides a valuable model with which to study more complex metabolic differentiation processes that operate in higher animals and plants, the aim being to establish the basic mechanisms of control of gene expression as a cell switches from vegetative growth to formation of a differentiated structure. Not surprisingly, this upsurge of interest in microbial differentiation has generated texts and symposium proceedings, many of them excellent in their way although they are mostly multi-authored volumes.

The main attraction of the text written by Smith and Berry, which restricts itself to differentiation in fungi, in which so many of the attractive systems are to be found, is that it is of a piece and does not suffer from the 'bittiness' that comes so often with a collection of articles writen by different authors. The first of eight chapters deals with the conceptual basis of morphogenesis, and includes fundamental information on regulation of gene expression and enzyme action in cells. There follow two chapters on development in the slime moulds Dictyostelium discoideum and Physarum polycephalum, two very popular organisms for studying differentiation in multicellular systems. The fungal spore, the vegetative state, and asexual and sexual reproduction are the subjects of the chapters that follow, and the text concludes with a chapter entitled 'Differentiation, secondary metabolism and industrial mycology' describing production of compounds such as organic acids and antibiotics by moulds in what is essentially differentiation at the level of chemical synthesis as distinct from morphology.

The book has many attractive features. Each chapter ends with a brief summary, which will make it a valuable teaching text. Although at first sight there may seem to be too great an emphasis on fungal differentiation processes that have as yet been poorly researched, this is in many respects a richness for in this way the molecular biologist and biochemist can become acquainted with some of the more esoteric, but in differentiation terms very attractive, regions of mycology.

There are surprisingly few 1973 or 1974 references, which means that the book will quickly become dated. In general, Academic have done a fine job in producing the volume, although this was not helped by the authors electing to use line drawings of organisms rather than photomicrographs or electron micrographs, as well as some very old diagrams of life cycles. The text would have fulfilled its aim of providing an introduction to the biochemistry of fungal development if it had dealt in rather more detail with the molecular basis of regulation of gene expression and enzyme action. There is, for instance, no reference to specific degradation of enzymes or of enzyme inactivation by chemical modification such as adenylylation.

The attractive features of the text, however, far outweigh these reservations, and it should prove a popular introduction for the teacher and for the researcher who wishes to enter this most challenging and fast developing area of biological research.

Anthony H. Rose 